\title{
The IGCP 509 Database System: Design and application of a tool to capture and illustrate litho- and chrono-stratigraphic information for Palaeoproterozoic tectonic domains, large igneous provinces and ore deposits; with examples from southern Africa.
}

\author{
Bruce M. Eglington ${ }^{1}$, Steven M. Reddy ${ }^{2}$ and David A.D. Evans ${ }^{3}$ \\ ${ }^{1}$ Saskatchewan Isotope Laboratory, University of Saskatchewan, 114 Science Place, Saskatoon, Saskatchewan, \\ S7N5E2, Canada (bruce.eglington@usask.ca); \\ ${ }^{2}$ The Institute for Geoscience Research, Dept. of Applied Geology, Curtin University of Technology, GPO Box \\ U1987, Perth, WA6845, Australia (s.reddy@curtin.edu.au); \\ ${ }^{3}$ Department of Geology and Geophysics, Yale University, New Haven, U.S.A (dai.evans@yale.edu).
}

\section{Abstract}

The IGCP 509 project is collating global information for the Palaeoproterozoic Era through the activities of numerous international collaborators. A database system (StratDB) and web interface has been designed to facilitate this process with links to an existing geochronology database (DateView). As a result, all information captured will remain available in a digital format for future researchers. The philosophy and design of the database and some of the outputs available from it are described. One of the principal features of the system is that it facilitates the construction of time-space correlation charts using an innovative application of GIS technology to non-geographic information, which permits users to query a variety of attribute information associated with lithostratigraphic units, metamorphic and deformation episodes associated with user-selected tectonic domains, large igneous provinces and major ore deposits. In the process, much of the manual labour normally associated with the construction of such charts in standard graphical or drafting packages is avoided. Associations between units, deformation, metamorphism, large igneous provinces and ore deposits may become more apparent once linked information is available for querying and investigation. Geochronological information from the DateView database may also be linked to entities stored in StratDB. GIS maps may be linked to the attribute information in StratDB and DateView to construct a variety of time-slice maps or 
palaeogeographic reconstructions with the same symbology as is used in the time-space correlation charts. This database system will facilitate the dissemination of lithostratigraphic information for many countries to a broader community and will help non-specialists to easily view information for various Palaeoproterozoic tectonic domains.

The system is illustrated using a preliminary compilation of information for the Palaeoproterozoic of southern Africa. The correlation charts and time-slice maps provide insights to the geological evolution of this region which emphasise some aspects and correlations which have not previously been extensively considered; for instance possible correlation of units in the central and western zones of the Limpopo Belt (South Africa, Zimbabwe and Botswana) with the Magondi Belt of Zimbabwe and its extension into northern Botswana.

\section{Introduction}

The IGCP 509 project seeks to collate global information for the Palaeoproterozoic Era, with the express objectives of developing a thorough database of the geological record with up-to-date geochronological constraints and to produce global time-space correlation charts. In order to meet these objectives, published and new information is being compiled by numerous researchers, coordinated by more than 20 regional experts. With so many individuals, drawn from a wide variety of sub-disciplines within the earth sciences, varied organisations, cultures and languages, it was decided to establish a database system to facilitate data capture, sharing and standardisation and to provide standardised software for producing time-space correlation charts derived from information in the database. An added advantage of this approach is that all information captured will remain available in a digital format for future researchers. Here, we describe the philosophy and design of the principal database employed by participants in the IGCP 509 project, its links to other allied database systems, and illustrate some of the outputs available. Example outputs are based on an initial compilation of the geology and geochronology of Palaeoproterozoic southern Africa.

The principal database system used for the IGCP 509 project is the StratDB database which provides storage of lithostratigraphic, tectonic domain, large igneous province and ore deposit 
information. Geochronological information is drawn from the DateView database. Figure 1 provides a schematic view of the major components comprising the StratDB and DateView databases and their associated links. Both the StratDB and DateView databases are available on the web at http://sil.usask.ca/databases.htm.

Figure 1 about here

We also describe the general methodology adopted for the construction of time-space correlation charts. The approach used is an innovative application of GIS technology to non-geographic information so as to benefit from its ability to query and portray attribute information associated with polygons. In the process, much of the manual labour normally associated with the construction of such charts in standard graphical or drafting packages is avoided. Although some compilations have produced flexible legends for GIS maps (for instance Steinshouer et al., 1999; Raines et al., 2007), we are not aware of any equivalent use of GIS technology in the manner instituted here. In addition to creating correlation charts, the system permits users with access to appropriate digital GIS data sources (via shapefiles, geodatabases, etc) to produce maps using exactly the same graphical symbology as for the charts.

\section{Origin of the Database Systems}

StratDB is a web-enabled extension of an earlier desktop system which captured information for lithostratigraphic units recognised by the South African Committee for Stratigraphy (Eglington $e t$ al., 2001). Several enhancements were specifically developed for the IGCP 509 project, in particular to facilitate the capture of rock-type and geodynamic setting information for lithostratigraphic units; summary information for multiple metamorphic and deformation episodes within tectonic domains; large igneous province information and summary attributes for ore deposits. StratDB also provides links to geochronological information stored in the DateView database. Aspects of this geochronology database system have previously been described by Eglington (2004) and Eglington and Armstrong (2004).

Many of the concepts adopted for outputs from the StratDB system are based on correlation charts produced by previous compilers e.g. Hartzer et al. (1998), Wardle et al. (2002) and Ansdell et al. (2005), all of which were produced using standard commercial graphics packages. 


\section{Database Design}

The principal tables in the StratDB database contain essential information for each lithostratigraphic unit, structural domain, ore deposit and large igneous province (Figure 2). Other tables provide referential, look-up values or linkage fields to draw together additional information from various of the database tables. Another group of tables within the database (Figure 3) stores additional information for use in the construction of the time-space correlation charts.

The database utilises a relational structure with full referential integrity and normalisation. It is designed so that data integrity is constrained by a series of primary and foreign keys. Records (new or modified) may not contain values which do not already exist in master tables and these tables also act as 'look-up' sources to facilitate the construction of user queries. Any changes made to 'master' key field values are automatically propagated to all linked tables and records.

Figure 2 about here

The principal table in the StratDB database contains information defining the lithostratigraphic units. Each unit has a unique integer ID and is associated with one country. If a unit with the same name occurs in more than one country, then additional unique records need to be created for each country. Unit names are stored in Unicode strings so as to handle non-western characters. All non-numeric primary and foreign keys, however, require ASCII characters. Each unit is recursively linked to a 'parent' unit via a ParentID field so as to create hierarchical relationships between units. The relative order of subunits in these hierarchical relationships is maintained by a longer integer ( 4 byte) ‘sort order’ field. For maximum flexibility, this field expects a value representing the minimum age of the unit in years. Minimum and maximum estimates for the age of a unit (in Ma) are also stored in appropriate fields. Other fields in this table store information on the rank of the unit and the status of the unit, for instance, whether the name is officially recognised, informal, historical, etc. Descriptions of a unit, stored in a BLOB field, are invaluable for users who do not know the local geology well. 
Two important tables, for the IGCP 509 project, hold information on the dominant rock class and geodynamic settings for each unit. Some of the acceptable values for these two characteristics are shown in Figure 2. These values are instrumental in illustrating the nature of each unit in the time-space correlation charts. The depositional setting of units (e.g. fluviatile, shallow marine, deep marine, etc) may also be captured and used as attributes for correlation charts and maps. Dominant palaeocurrent directions for sedimentary units may also be captured so as to facilitate comparisons across country boundaries and in palaeogeographic reconstructions.

All lithostratigraphic units are associated with hierarchical ranks. Each rank has an associated rank width which controls the width of the rectangular polygons for the time-space correlation charts. Higher level units are plotted as wider boxes. Each unit is also linked to chronostratigraphic timescale intervals (stages, periods, etc), utilising the terms recommended by Gradstein et al. (2004). Links should be made at the lowest possible classification possible e.g. stage rather than period if an appropriate stage exists. A hierarchical list of chronostratigraphic timescale intervals with associated minimum and maximum ages may be downloaded as an Excel spreadsheet.

If GIS map attribute information is available for units, it is useful to also capture the unique GIS identifiers used in the GIS system. Some GIS coverages and shapefiles use unique integer values for units whereas others use unique strings. Either can be stored in the StratDB database and associated with the unique unit record number used by the database. With this information in place, it is possible to link any of the attribute data from the database to GIS maps, as was done by Eglington and Armstrong (2004) for the ages of units in the Kaapvaal Craton. In future, once the OneGeology initiative (www.onegeology.org) provides a web file sever (WFS) service in addition to the initial web map server (WMS) service, it ought to be possible to link attribute data in StratDB to the various OneGeology maps.

Other tables hold information specifying which units precede or succeed one another and details of which units are correlatives or synonyms for the current unit. If information is added for either preceding or succeeding units, the software can add the reverse relationship. The intention is to capture information for definitive relationships, not necessarily for every contact. Correlatives are 
equivalent units recognised as different units, whereas synonyms are alternative terms used for exactly the same unit and outcrop area. In most cases, synonyms are historical unit names which should no longer be used. In addition to providing useful insights to the lithostratigraphy of an area, these links facilitate navigation between units in the web browser interface.

Each tectonic domain also receives a unique integer ID and is associated with a hierarchical parent via a 'parent ID' number. Associated central latitude and longitude values facilitate queries to extract information from the database within user-selected geographic limits without implementing a WFS capability. Various episodes of deformation receive unique integer 'order' numbers and each episode of deformation has a minimum and maximum age. Each episode is also associated with an orogeny, which permits people who don't know the regional geology to select domains associated with more wide-spread orogenesis. Deformation style (e.g. ductile, brittle) and vergence direction (at 45 degree increments) may also be stored. Similarly, metamorphic episodes within the domain have unique integer IDs. The age of peak metamorphism and its plus and minus 95\% uncertainties are also stored, together with the typical grade of metamorphism for the domain, plus estimates for minimum and maximum peak temperature and metamorphism and the associated orogeny.

In order to construct time-space correlation charts, units and domains need to be associated with unique charts which any user of the system may create. Charts are not shared by groups of users; each user creates their own by defining the order (from left to right across a chart) in which tectonic domains are to be drawn. However, the information associated with each domain (lithostratigraphy, metamorphic and deformation information, etc) is common to all users. Figure 3 illustrates the principal features of the database tables and links used to construct the outputs which are subsequently imported to a GIS system for final compilation of the charts. All point locality geographic information stored in both StratDB and DateView should be relative to the WGS84 datum.

Figure 3 about here 


\section{Hardware and Software}

The data are stored in a Firebird open-source client/server type relational database management system which provides full referential integrity. Although open-source, Firebird provides similar capabilities to major commercial database systems such as Oracle and is very easy to manage. The web interface to the database was programmed using the Delphi language, utilising Intraweb, TeeChart and Flexcel components. The database server is currently located on a standard Pentium 4 computer with 512 Mb memory, running the Red Hat Linux operating system. Web interface programs for each database are standalone web servers, running as services on a standard Windows XP, Pentium 4 computer with 1 Gb of memory. Browsers currently supported by the web servers are Internet Explorer, Firefox, Netscape (versions 6 and 7), Opera and Safari.

All access to the database has been coded using dbExpress components within Delphi, which has the advantage that the data can be ported to other client-server database systems with minimal change to the software code, provided that these database systems support triggers, generators and BLOB fields. Intraweb was chosen for the web interface since it speeded up the programming considerably. Most web database connections are stateless i.e. the database does not maintain any memory of previous requests from a user. Whilst effective for simple reads from a database, this approach introduces considerable programming and network overheads when inserting new information or updating existing information in a database. Intraweb provides a stateful interface. In addition, the programming environment is much closer to traditional graphical user interfaces (GUI), which also speeded up development of the software. As a result of this stateful control, the normal 'back' button in browsers is disabled and navigation has to be performed by appropriate links programmed on each web page. TeeChart is a rich graphing component which integrates well with Intraweb and is easily modified to achieve the various graphs required by both StratDB and DateView. It also provides the ability to display GIS shapefiles, which is important for illustrating the geographic location of samples in DateView. Flexcel is a component for importing and exporting spreadsheets in Excel format. It has the advantage that templates can be designed using Excel and stored outside of the program executable. As a result, spreadsheet formats for downloading information are easily changed without the need to recompile any software. Flexcel also provides access to most Excel capabilities, the most important of which for these database interfaces has been the use of 
outlines to facilitate grouping of data (in StratDB) and the use of pivot tables to organise data for different variables measured for many samples (in DateView).

All user access to the system is controlled via a separate Firebird database which contains user information such as user ID, passwords, email addresses and access permissions. When users log in, this system is queried to determine the user's allowed access rights and to upload any stored information for the user, for instance the definition terms of the user's last query.

Administration of the database, including regular backups, sweeps, design changes, etc, is performed using a commercial GUI package, IBExpert.

Time-space correlation charts are created using GIS (geographic information system) technology. Although the data in the charts are not geographic, the $\mathrm{x}$ (offsets from an arbitrary origin) and $\mathrm{y}$ (age) information may be cast as a Cartesian problem in which the node values permit the construction of rectangles (polygons in GIS terminology) with associated attribute information (Figure 4). These attributes may be flexibly queried and used to construct the charts using any GIS package. We experimented with several products and have used ArcGIS from ESRI because it is available at most universities and geological organisations, and it provides style sheets which facilitate easy changes to the symbology used to portray different rock classes, geodynamic settings, etc.

Data are downloaded from the database as Microsoft Excel files, which are then imported to an ArcGIS personal geodatabase using Microsoft Access, ESRI ArcCatalog and ArcMap. Values for the vertices of the various polygons are derived from the minimum and maximum ages of each unit, LIP or episode of metamorphism or deformation, cast as negative values so that the youngest events will be at the top of a chart. The left side of each polygon is defined by an offset for each unit into the space allocated for each domain. The width of polygons is controlled by the 'rank width’ parameter stored for each rank. Hierarchically higher level units have larger rank widths and thus plot as wider boxes. Various parameters which control the layout of the timespace correlation charts are illustrated in Figure 3. Creation of polygons and bounding polylines from initial point feature classes is performed using the free ET Geowizards plug-in for ArcMap. 
Figure 4 about here

\section{Functionality}

\section{User-specified options}

Users may modify and save various options which impact on the output of database queries. At present, this is limited to selecting whether to show associated geochronological records from the DateView database and whether to limit records to hierarchical ranks above those of seams (i.e. member rank and above). In part, these options are intended to reduce the time needed to run queries for situations where the extra information is not needed.

\section{Querying the database}

Queries against the database are defined in a series of up to three windows. The first requires users to select which continents are to be included in the query. The second window (for unit queries) shows all countries in the previously selected continents which have records in the database. If one wants all possible units from all available countries, one may omit checking the checkbox above the list of countries. The third window lists all lithostratigraphic units in the selected countries, plus lists of selectable values for variables such as: minimum age; maximum age; minimum and maximum sort order values; tectonic domains; reference sources; validation status; chronostratigraphic periods.

In the case of domain queries, users have the option to select from a list of orogenies and domain types (province, terrane, etc), in addition to a list of domain names associated with the userselected continents.

A checkbox is associated with each query parameter so as to reduce the impact of changing which variables are selected during a session. For instance, assume one selected some specific units within an age range, ran the query and then decided to see all units within the same age range. For the first query, one would check the checkboxes for units, minimum age and maximum age and provide appropriate values for these fields. For the second query, all that is required is to uncheck the units checkbox. If one then wants to repeat the first query, it is not 
necessary to select each unit again; one only needs to re-check the unit's checkbox. All unchanged selections are remembered during a session and, if checked, are stored in the user database for when user's next log in, provided that user's logout by clicking on the "log out” hot link.

\section{Modifying the database}

The default access permission for new users is read-only but users wishing to modify existing records or insert new records may contact the database administrator to request modify/insert rights. Users with modify permission for the StratDB database see a button with the caption "Edit" on several of the detail forms. It is necessary to click on this button to go into edit mode, at which point editable fields are enclosed by box outlines or show drop-down boxes. Once changes

have been made, one must click on the "Save" button to update the information in the database. If one moves to another record without saving, all changes made are lost. If one realises that a mistake has been made one may either correct the mistake or click on the "Cancel” button. It is important to realise that every view of the database contents is a 'snap-shot' of the situation when a query is run and is held in memory. Users never edit the database itself, only a copy of the information. Changes to the database are automatically managed by the relational database management system, based on what is changed and when it is changed. Thus multiple users may edit different parts of the same record and the software will update those that require changes when users activate the save process. Other users will see these changes the next time information is read from the database.

There is also a button on this form to export the lithostratigraphic unit name, unique database ID and some other information to the DateView database. Anybody wishing to add data to DateView is encouraged to first add the unit information to StratDB as this will ensure that the two databases are correctly linked without the need for manual editing of the DateView database. When appropriate links are in place, 'published' geochronological information added to DateView for a unit will automatically be visible in StratDB without the need to manually edit several tables in DateView. 
For security, only a very limited number of individuals have permission to delete records from the database. When a master record is deleted, other 'detail' records which have referential integrity links are automatically also deleted. Incorrect deletion of records in the database could thus lead to substantial loss of information which can only be recovered from backups.

\section{Adding data to the database}

Only some fields for lithostratigraphic units may be inserted online. This is, in part, because of the complexity of adding records for all associated tables and the rather tedious, slow process involved in doing this one record at a time. Most initial data capture is performed offline, using either a Microsoft Access database template or a series of Microsoft Excel spreadsheet templates, as described at http://sil.usask.ca/sdb_compilations.htm. Once the basic data are in the database, additional attribute information such as GIS links, references, associations with tectonic domains, may be added online.

\section{Raising an objection to a record}

An important feature of the database software, which will facilitate peer review of information, is the ability for any user to 'raise an objection' to any record. Users doing so enter text describing their reasons for disagreeing with the information currently in the database. Various volunteers with regional or topic-specific expertise act as moderators (validators) for information in the database. They are tasked with adjudicating any objections raised so as to either achieve a compromise or add additional records to capture significantly different interpretations. The validation status of records may also be used as a search term.

\section{Confidentiality of information}

The DateView geochronology database is designed to allow storage of confidential information e.g. personal, unpublished dates. Access to all information is controlled by user permissions and these permissions are controlled across both the DateView and StratDB database systems. Hence, users with personal information in linked fields in DateView will be able to see these data from StratDB whilst most users will only see records marked as "public". Only those DateView records which have interpretations set as intrusion, extrusion, detrital, or diagenesis (for units); or as metamorphism or cooling (for domains), are visible in StratDB. Other isotope data are not shown at present. 


\section{Outputs from the Database}

A number of outputs from the database are available, most of which are activated from menu links at the left of the main menu. In all cases, the results of a query are provided as a grid. From this grid, one may click on the unit (or other) ID hotlink to drill down for more information on the chosen unit, LIP, domain or deposit. Once one has selected a specific entity (Figure 5), one may navigate down or up the hierarchy by either clicking on hotlinks associated with each subunit or by clicking the "Go to parent” button. Links are also provided to information such as tectonic settings, rock class, chronostratigraphic period, references, GIS links, etc.

Figure 5 about here

Geochronological information for the current unit and all units that are hierarchically one level lower may be extracted from the DateView database if link-fields exist. Some other outputs, designed for export to Excel spreadsheets, are described below:

\section{Listings of Look-up tables}

Users may download Excel spreadsheets containing the contents of several of the master (lookup) tables. Contributors should check on up-to-date values for the various tables prior to compiling information in the Microsoft Access and Excel templates.

\section{Lithostratigraphic hierarchy}

The results of a query may be downloaded as an Excel spreadsheet, as illustrated in Figure 6. The contents of the spreadsheet are grouped using the outline capability of Excel and sorted according to values of the 'sort order' variable so as to illustrate the hierarchical relationship between units. Similar capabilities exist or are planned for tectonic domains and for large igneous provinces

Figure 6 about here

\section{Time-space correlation charts}

In addition to providing a long-term resource for researchers, StratDB and DateView also allow project participants to query the databases and produce outputs for use in the construction of time-space charts. The web interface provides data output in a format suitable for construction of time-space diagrams using standard GIS software such as ArcMap, MapInfo or UDig. The 
diagrams are queryable using various attribute information, such as Rock Class, Geodynamic Setting, Depositional Setting, etc. The system has been tested, using ESRI ARCGIS versions 9.1 and 9.2, and testing is ongoing as more 'real' data are added. More information on the specific procedures to follow when creating time-space correlation charts is provided in separate documentation available from http://sil.usask.ca/databases.htm.

The principal legend for the space-time charts is illustrated in Figure 7. This legend is based on the one used for previous compilations of Canadian Palaeoproterozoic terranes (Wardle et al., 2002; Ansdell et al., 2005), but with data shown as a matrix derived from two properties: rock class and geodynamic setting. With the pseudo-GIS approach utilised, each of the attributes associated with individual rectangles on the chart is selectable, making for a very flexible resource. Specific colours and symbology for the geodynamic setting - rock-class matrix are derived from an ESRI ArcGIS style sheet and can thus be easily changed to suit the requirements of all IGCP 509 project coordinators without any time-consuming recoding by participants. The level of certainty for the minimum and maximum age limits determine the outline style of bounding polygons.

Figure 7 and Figure 8 about here

An alternative time-space correlation chart, utilising information on depositional environment may also be produced. The legend for this type of chart is illustrated in Figure 8, together with some other attribute information which may be plotted with either form of chart. Additional attribute information, such as special features of units (e.g. units exhibiting ${ }^{13} \mathrm{C}$ isotope excursions) or geochronological information, may be plotted as point symbols. Values and symbols for these attributes are shown in Figure 8. Figure 9 provides a miniature version of a time-space correlation chart constructed for the Palaeoproterozoic of southern Africa, to illustrate the general layout of the charts with space for titles, authors, locality maps, legend and the various tectonic domains. Full size versions of the Rock Class - Geodynamic Setting and of the Depositional Environment time-space correlation charts for southern Africa are available as supplementary files (online from the Geological Society, London). In the charts, smaller polygons are plotted on top of larger ones based on the rank width of the polygons, utilising 
queries within ArcGIS. Polygons for all plutonic and hypabyssal intrusions are offset to the right of sedimentary and volcanic units to emphasise their intrusive relationship. Labelling (not shown on the miniature version in Figure 9 because of size constraints) is automated, using default options in ArcMap. The label positions may, however, be modified manually if so desired.

Figure 9 about here

\section{Time-Space Correlation Chart for southern Africa}

A number of features of the time-space correlation charts which may be produced for the IGCP 509 project are illustrated in the following figures, based on examples drawn from a preliminary compilation of data for the Palaeoproterozoic of southern Africa. Capabilities and limitations of this approach to creating charts are also described. A more detailed assessment of the Palaeoproterozoic geology of southern Africa, together with more comprehensive crossreferencing of published literature sources, will be presented elsewhere towards the end of the IGCP 509 project.

The area covered by the Palaeoproterozoic compilation for southern Africa is illustrated in Figure 10, which also shows the extent of the various tectonic domains considered. The backdrop to this diagram is a compilation of aeromagnetic anomalies provided by the Council for Geoscience, South Africa, some features of which are important in defining domain boundaries and in regional correlations. The domain polygons are drawn from a separate GIS database or from individual shapefiles, not from the StratDB database.

Figure 10 about here

Figure 11 illustrates the lithostratigraphy and metamorphism for the interval from 2300 Ma to 1800 Ma. Here, we illustrate that it is possible to compile and present different correlation schemes, for instance that of the South Africa Committee for Stratigraphy (SACS) (as most recently summarised by Eriksson et al. (2006) and Moen (2006)) and more recent work based on dating of detrital zircons in sediments of the Kimberley domain. This recent work (Dorland, 2004) has recognised that the Lucknow and Mapedi units, previously considered to be part of the 
Olifantshoek succession and coeval with the Waterberg Group, are much older and are actually coeval with units of the Segwagwa and Pretoria Groups (upper Transvaal Supergroup). The Lucknow and Mapedi units are therefore proposed to form an Elim Group which succeeds the Postmasburg Group in the Kimberley domain (Dorland, 2004). This recent correlation places ${ }^{13} \mathrm{C}$ isotope excursions (blue squares in the figure) in the Lucknow Formation (upper Elim Group) and Silverton Shale (Pretoria Group) at similar ages (Bekker et al., 2009). Hartley basalt volcanism in the Kimberley domain (Cornell et al., 1998) is coeval with dykes in the Kanye domain but precedes other, younger post-Waterberg dykes in the same domains (Hanson et al., 2004). Thermal metamorphism associated with the Bushveld Complex (Witwatersrand domain) and coeval intrusions in the Kanye and Kimberley domains, is distinct from deformation, metamorphism and igneous activity associated with the Vredefort impact event (see DateView database for age information). At least two separate episodes of glacial activity (large $\mathrm{X}$ symbols) are evident in the lower part of the upper Transvaal succession (Postmasburg and Pretoria Groups).

The geodynamic setting of the units was initially epicratonic but was succeeded by collisionrelated activity during deposition of the Waterberg Group. Epicontinental sedimentation resumed along the western margin of the Kaapvaal Craton after about 1930 Ma, possibly with some faulting or thrusting subsequent to formation of the Neylan Formation (not labelled) and Hartley basalts, but prior to deposition of younger units of the Olifantshoek succession (Tinker et al., 2002). There is, however, no sign of significant (Kheis) orogenesis in the Kimberley domain during this interval of time, a point that has been made previously (Eglington and Armstrong, 2004; Eglington, 2006).

Figure 11 about here

Depositional environments for the Transvaal Supergroup varied considerably (Figure 12). The lower part of the succession was dominated by shallow to deeper marine environments with deeper facies predominating along the western edge of the Kaapvaal Craton (Dorland, 2004; Coetzee, 2001; Eriksson et al., 2006; Sumner and Beukes, 2006). Recent dating (Dorland, 2004) 
suggests that conventional correlation of the Black Reef Formation (Kanye, Witwatersrand and Pietersburg domains) with the Vryburg Formation (Kimberley domain) is incorrect. His work suggests that the Black Reef conglomerates are considerably younger than the Vryburg sediments and that a correlation with the Motiton Member, Monteville Formation is more likely. After an almost 100 Ma hiatus in sedimentation (or at least no preservation), sedimentation resumed with more proximal sediments dominated by fluvial and lacustrine settings although marine environments continued along the western edge of the Kaapvaal Craton (Kimberley domain). A prominent episode of volcanism formed the Ongeluk, Tsatsu and Hekpoort units. Age constraints on the succession are provided by zircons from tuffs in the lower Transvaal succession in the Kimberley domain but very few direct geochronological data are available in the other domains.

Plutonic igneous activity is recorded in the Pietersburg domain (ages based on recalculation of multiple bulk zircon analyses National Physical Research Laboratory, Council for Scientific and Industrial Research; see DateView database) and was coeval with the deposition of carbonate sediments in the same domain and with the latter stages of plutonism in the central zone of the Limpopo Belt (Figure 9 and full size charts). This association presents some conceptual problems and highlights the benefits of time-space correlation charts for emphasising issues warranting further investigation. In this case, how does one juxtapose plutonic igneous activity and contemporaneous deposition of marine carbonates? Possibly this could be explained by considering the geographic distribution of the units concerned, an aspect that can not be illustrated on time-space correlation charts alone. Another issue with the current approach to constructing the rectangles (polygons) for igneous units is that their vertical dimension is controlled by either real duration of activity or the uncertainty of the ages. In the case of the Moletsi granite, the range in age is due to age uncertainty and not due to a long duration of igneous activity. Some way to distinguish between, and illustrate, these two options would be useful but, other than to use different line styles for the polygon borders (as is currently provided), this issue is not resolved. In some cases, sedimentary units have similar limitations but usually, the relationship between units within a hierarchical succession provides some limitation on possible minimum and maximum ages where geochronological constraints are absent or insufficient. 
Figure 12 about here

Igneous and metamorphic activity associated with the Bushveld igneous event and with the Limpopo Belt are two distinct events, as shown in Figure 13. Most dates for 2 Ga activity in the Limpopo Belt are from the Central and Western zones of the Belt. Dates associated with lower temperature closure of isotope systems are not shown but help define the age limits and grades of metamorphism in the various domains constituting the Limpopo Belt. The age span of metamorphism and deformation suffers from a similar problem to that of plutonic igneous activity. The interval for high grade metamorphism in the central zone of the Limpopo Belt is well constrained by numerous zircon and monazite ages but medium to high grade metamorphism in the Magondi Belt is largely unconstrained. In this latter case, metamorphism must be younger than deposition of the Piriwiri and Lomagundi sediments (also poorly constrained) and older than post-tectonic granitoids. The exact duration and extent to which metamorphism and plutonism might be diachronous is not easily illustrated in time-space correlation charts intended to provide a broad, regional perspective.

Deposition of sediments along the north western margin of Zimbabwe (Deweras and younger Piriwiri and Lomagundi successions) must have been essentially contemporaneous with deposition of the upper Transvaal sediments on the Kaapvaal Craton (here illustrated only for the Pietersburg domain) and with sediments of the Gumbu Group (Buick et al., 2003) in the Limpopo Belt and of sediments encountered during drilling at Gweta and at Sua Pan, Botswana (Mapeo et al., 2001; Majaule et al., 2001). 2.0 Ga to 1.93 Ga post-tectonic igneous activity is recorded from the Magondi Belt of NW Zimbabwe (McCourt et al., 2000; Munyanyiwa et al., 1997; Treloar and Kramers, 1989), effectively providing a minimum age for Lomagundi and Piriwiri sedimentation. Metamorphism in the Magondi Belt is broadly contemporaneous with that in the Limpopo Belt. Indeed, sediments with similar depositional and metamorphic ages follow the arcuate trend in aeromagnetic anomalies evident in Figure 10 (see also Figure 14). Several of these sediments and time-equivalents on the Kaapvaal craton also exhibit major ${ }^{13} \mathrm{C}$ isotope excursions (note blue squares on figure) (Buick et al., 2003; Bekker et al., 2009; Schidlowski et al., 1976), and have been inferred to represent a single perturbation in the carbon isotope composition of marine carbonates. Traditionally, the Magondi Belt has been thought to extend 
southwards along the western margin of the Kaapvaal craton to join up with the Kheis Belt (Hartnady et al., 1985). Eglington and Armstrong (2004) and Eglington (2006) have emphasised, though, that there is no geochronological evidence for a major $\sim 2 \mathrm{Ga}$ orogeny normally envisaged for the south western margin of the Kaapvaal Craton. Eglington and Armstrong (2004) also drew attention to the arcuate aeromagnetic anomaly pattern around the western, south western and southern margins of the Zimbabwe Craton. Several earlier studies have also commented on or illustrated possible links of the Magondi and Limpopo Belts (Mapeo et al., 2001; Hartnady et al., 1985; Ranganai et al., 2002). The time-space correlation charts (Figure 9 and Figure 13), GIS maps of coeval units (Figure 14), geophysics (Figure 10) and geochronology (Figure 13) all appear to support a link between these two belts, reflecting Palaeoproterozoic movement of the Zimbabwe Craton to the south west. The various zones of the Limpopo Belt have traditionally been considered in isolation from the possible broader regional picture (Barton et al., 2006; Kramers et al., 2006) which may, in part, have contributed to disagreements as to the regional significance of $\sim 2 \mathrm{Ga}$ activity relative to Late Archaean activity (see Barton et al. and Kramers et al. for recent summaries). If the Zimbabwe Craton was an indenter into early Proterozoic sediments around its western, south western and southern margins, then this has significant implications for the palaeogeographic evolution of the region and for mineral exploration.

Figure 13 about here

\section{Time-slice Maps Illustrating Lithostratigraphic Evolution of Southern Africa}

Since the StratDB database permits one to store link field values for individual units in different GIS maps, it is very easy to construct time-slice maps which illustrate the development of the domains included in the correlation charts. Example maps for southern Africa, produced from data exported from StratDB and linked to GIS information from five different map compilations, are illustrated in Figure 14. Here, the maps illustrate the Rock Class - Geodynamic Settings and the Depositional Environment attributes stored in StratDB but a similar approach could be used for any attribute information from the database or from offline compilations which use the unique unit ID’s created for StratDB. These GIS compilations provide a useful insight into the 
progressive development of crust during the Palaeoproterozoic of southern Africa. Early epicontinental, mostly marine sedimentation dominated by carbonate and then ironstone lithologies spread across the Kaapvaal Craton with some plutonic and late metamorphic igneous activity continuing in parts of the Limpopo Belt. This was followed by continued epicontinental sedimentation in fluvial and lacustrine to shallow marine settings on the Kaapvaal Craton and along the NW and SW margins of the Zimbabwe craton. Marine facies were most common along the western margins of both cratons. Fault-bounded basins associated with sinistral collision and movement of the Zimbabwe Craton relative to the Kaapvaal Craton then provided repositories for collision-related sediments of the Waterberg Group and Soutpansberg Group subsequent to 2.05 Ga. Clastic, epicontinental sedimentation continued on the western margin of the Kaapvaal Craton. Sparse evidence for sedimentation from 1700 - 1600 Ma is preserved along the western margin of the Kaapvaal Craton and in Botswana.

Figure 14 about here

The time-space correlation charts and time-slice maps highlight avenues for further research. Extension of the maps and correlation charts back in time may help elucidate the earlier (Late Archaean) evolution of the Limpopo Belt by providing inter-regional perspectives and data compilations otherwise not always available or freely accessible.

\section{Future Directions}

StratDB and DateView are both a work in progress and are still under active development as suggestions for improvements are received from the user community. This development proceeds along several fronts.

First, the database design can be modified or extended. StratDB provides a very useful central system in which information for lithostratigraphic units, tectonic domains, large igneous provinces and ore deposits is captured. Each record receives a unique database ID which may be used as a common link field value by external databases storing information for other purposes. For instance, palaeomagnetic information stored in an external database could include the StratDB unit ID and so facilitate linking of the two databases or StratDB could be modified to 
store unique ID values (as used by the external database) for each palaeomagnetic pole. Geochemical data for units may be stored in a similar way. The DateView geochronology database also utilises the same unique unit ID and could be linked to a palaeomagnetic database to show all available ages associated with specific poles, in the same way that StratDB currently draws age information for lithostratigraphic units, tectonic domains, large igneous provinces and ore deposits from DateView. The database design also provides links to GIS shapefiles, geodatabases, coverages, etc, which may facilitate enhanced spatial interfacing of the data in future and could be used to plot the location of igneous or metamorphic activity, mineralisation, etc for plates after rotation about selected Euler poles. Another area of application for both DateView and StratDB is with efforts to capture information for magmatic activity associated with large igneous provinces. Ernst and Buchan (2001) have already compiled a database of many of these episodes and the geochronological data used by Prokoph et al. (2004) have been imported to DateView and to StratDB. Association of these records in StratDB with unique lithostratigraphic unit IDs will facilitate future linking of these data whilst also providing continued updating of the geochronology as new data become available for the various plutonic, hypabyssal and volcanic intrusions. Ore deposit information has been imported from the Geological Survey of Canada's (GSC) global ore deposit database and contains links to locality, clan type, mineralisation age, host unit and major commodities. Addition of data from other economic databases and links to these systems are envisaged. An advantage of such linkages is that new data added to any one database are immediately visible to other systems such that users may concentrate on their own fields of expertise, yet still draw on information compiled by experts in other sub-disciplines.

Secondly, the user interface will also require updates as user requirements grow and change. At present, all software development is by one of us (BME) but, hopefully, others will play a role in future. The Delphi language currently used for development can not handle Unicode strings, but this will change with the release of the next version of this software in late 2008 and full international language support will then be provided. The present interface is entirely via a browser interface but other web interfaces will no doubt become necessary. Possibilities include accessing data from other web portals and systems using web services such as the simple object access protocol (SOAP). Controlling user permissions will, however, need to be addressed before 
this protocol is implemented. Alternatively, web services could be set up to provide only basic functionality and access to public records.

As time permits, it will also be useful to provide options for online capture of information, both for individual records and for batches of records. Graphs will also be added to illustrate the variation of detrital zircon age data (extracted from raw data stored in the DateView database) relative to interpreted stratigraphic age (the minimum age field) for each unit. Direct output of the information required to produce the time-space correlation charts to either shapefiles or a personal geodatabase would also be an advantage so as to reduce the effort required to produce these charts.

The database design is intended to facilitate control of the contents of the database by an interested community of collaborators, more of whom will hopefully accept the role of moderators (validators) for information in the database. Future involvement of other international interest groups, beyond IGCP 509, is also likely and will help ensure that the database remains a long-term resource which facilitates international earth science research. As with any database endeavour, continued relevance of the data captured will require the ongoing interest and involvement of the user community to ensure that changes in knowledge are reflected in the contents of the database and that the database remains available for use.

\section{Conclusions}

The StratDB database system described here will play a significant role in the achievement of several of the objectives of the IGCP 509 project. It will enhance the dissemination of lithostratigraphic information for many countries to a broader community and will help nonspecialists to easily view information for various Palaeoproterozoic tectonic domains. The database, its web interface and the outputs of the system will greatly facilitate the construction of standardised time-space correlation charts by leveraging other technologies such as GIS.

Although primarily intended at this stage to cater for the IGCP 509 project in its investigation of the Palaeoproterozoic, the design of the database is flexible and can handle data from all of Earth 
history. Rapid and easy comparison of domains, now widely separated on different continents, using the StratDB and DateView databases, coupled with the GIS charting and mapping technology described here, will greatly facilitate palaeogeographic assessments and enhance understanding of the Palaeoproterozoic development of the Earth. As the first and, to the best of our knowledge, only international databases of their kind, it is hoped that the design and implementation of StratDB and the associated DateView database will stimulate the collation of international data in a uniform structure which will benefit many earth science researchers in years to come.

\section{Acknowledgements}

This is a contribution to IGCP 509. UNESCO and the International Geoscience Programme are thanked for providing some funding to facilitate a workshop from which design enhancements for the database system flowed. CodeGear (previously Borland), AtoZed, TMS, Steema, HKSoftware and ESRI provided educational versions of their software. The Saskatchewan Isotope Laboratory, which hosts the databases, receives financial support for its infrastructure from the University of Saskatchewan. The Council for Geoscience, South Africa, and the geological Survey of Namibia provided digital copies of various maps and geophysical images which were invaluable in developing the database system and in creating some of the diagrams, charts and maps. We also thank all the regional coordinators and other contributors to the IGCP 509 project for their assistance in populating the database and for suggestions for improvements. Two reviewers, Sergei Pisarevsky and Narelle Neumann, provided several suggestions for improvements to the manuscript.

\section{References}

Ansdell, K.M., Heaman, L.M., Machado, N., Stern, R.A., Corrigan, D., Bickford, P., Annesley, I.R., Bohm, C.O., Zwanzig, H.V., Bailes, A.H., Syme, R., Corkery, T., Ashton, K.E., Maxeiner, R.O., Yeo, G.M. and Delaney, G.D. (2005). Correlation Chart of the evolution of the Trans-Hudson Orogen - Manitoba-Saskatchewan segment. Can. J. Earth Sci., 42, 761.

Barton, J.M., Klemd, R., and Zeh, A. (2006). The Limpopo Belt: a result of Archean to Proterozoic, Turkic-type orogenesis?, 315-332. In, Reimold, W. U. and Gibson, R. L. 
(eds.), Processes on the early Earth, Geological Society of America Special Paper, Geological Society of America, Vol. 405.

Bekker, A., Beukes, N.J., Holmden, C.H., Kenig, F., Eglington, B.M., and Patterson, W.P. (in press). Fractionation between inorganic and organic carbon during the Lomagundi (2.22$2.1 \mathrm{Ga}$ ) carbon isotope excursion. Earth Planet.Sci.Lett.

Buick, I.S., Williams, I.S., Gibson, R.L., Cartwright, I. and Miller, J.A. (2003). Carbon and U$\mathrm{Pb}$ evidence for a Palaeoproterozoic crustal component in the Central Zone of the Limpopo Belt, South Africa. J. Geol. Soc. Lond., 160, 601-612.

Coetzee, L.L. (2001). Genetic stratigraphy of the Paleoproterozoic Pretoria Group in the western Transvaal. M.Sc. thesis (unpubl.), Rand Afrikaans University, 212pp.

Cornell, D.H., Armstrong, R.A. and Walraven, F. (1998). Geochronology of the Proterozoic Hartley Basalt Formation, South Africa : constraints on the Kheis tectogenesis and the Kaapvaal Craton's earliest Wilson Cycle. J. Afr. Earth Sci., 26, 5-27.

Dorland, H.C. (2004). Provenance ages and timing of sedimentation of selected neoarchean and Paleoproterozoic successions on the Kaapvaal Craton. Ph.D. thesis (unpubl.), Rand Afrikaans University, 326pp.

Eglington, B.M. (2004). DateView: a Windows geochronology database. Computers and Geosciences, 30, 847-858.

Eglington, B.M. (2006). Evolution of the Namaqua-Natal Belt, southern Africa - a geochronological and isotope geochemical review. J. Afr. Earth Sci., 46, 93-111.

Eglington, B.M. and Armstrong, R.A. (2004). The Kaapvaal Craton and adjacent orogens, southern Africa: a geochronological database and overview of the geological development of the craton. S. Afr. J. Geol., 107, 13-32.

Eglington, B.M., Tucker, S., Wolmarans, L.G. and Johnson, M.R. (2001). Desktop implementation of South African lithostratigraphic unit database: Version 2.0. Council for Geoscience Open File Report, 2001-0027, 1-21.

Eriksson, P.G., Altermann, W. and Hartzer, F.J. (2006) . The Transvaal Supergroup and its precursors, 237-260. In Johnson,M.R., Anhaeusser,C.R. and Thomas,R.J. (eds.), The geology of South Africa, Geological Society of South Africa and the Council for Geoscience, Pretoria

Ernst, R.E. and Buchan, K.L. (2001). Large mafic magmatic events through time and links to mantle-plume heads, 483-575. In, Ernst, R. E. and Buchan, K. L. (eds.), Mantle plumes: their identification through time, Geological Society of America Special Paper, Geological Society of America, Vol. 352.

Gradstein, F.M., Ogg, J.G. and Smith, A.G. (2004) . Chronostratigraphy: linking time and rock, 20-46. In Gradstein,F.M., Ogg,J.G. and Smith,A.G. (eds.), A geologic timescale 2004, 
Hanson, R.E., Gose, W.A., Crowley, J.L., Ramezani, J., Bowring, S.A., Bullen, D.S., Hall, R.P., Pancake, J.A. and Mukwakwami, J. (2004). Paleoproterozoic intraplate magmatism and basin development on the Kaapvaal Craton: age, paleomagnetism and geochemistry of $\sim 1.93$ to $\sim 1.87$ Ga post-Waterberg dolerites. S. Afr. J. Geol., 107, 233-254.

Hartnady, C.J.H., Joubert, P. and Stowe, C.W. (1985). Proterozoic crustal evolution in southwestern Africa. Episodes, 8, 236-244.

Hartzer, F. J., Johnson, M.R., and Eglington, B.M. (1998). Stratigraphic table of South Africa. Council for Geoscience, Pretoria, South Africa.

Key, R.M. and Ayres, N. (2000). The 1998 edition of the National Geological Map of Botswana. J. Afr. Earth Sci., 30, 427-451.

Kramers, J.D., McCourt, S. and Van Reenen, D.D. (2006) . The Limpopo Belt, 209-236. In Johnson,M.R., Anhaeusser,C.R. and Thomas,R.J. (eds.), The geology of South Africa, Geological Society of South Africa and the Council for Geoscience, Pretoria

Majaule, T., Hanson, R.M., Key, R.M., Singletary, S.J., Martin, M.W. and Bowring, S.A. (2001). The Magondi Belt in northeast Botswana : regional relations and new geochronological data from the Sua Pan area. J. Afr. Earth Sci., 32, 257-267.

Mapeo, R.B.M., Armstrong, R.A. and Kampunzu, A.B. (2001). SHRIMP U-Pb zircon geochronology of gneisses from the Gweta borehole, northeast Botswana: implications for the Palaeoproterozoic Magondi Belt in southern Africa. Geol. Mag., 138, 299-308.

McCourt, S., Hilliard, P., Armstrong, R.A. and Munyanyiwa, H. (2000). SHRIMP U-Pb zircon geochronology of the Hurungwe granite north-west Zimbabwe : age constraints on the timing of the Magondi orogeny and implications for the correlation between the Kheis and Magondi belts. S. Afr. J. Geol., 104, 39-46.

Moen, H.F.G. (2006) • The Olifantshoek Supergroup, 319-324. In Johnson,M.R., Anhaeusser,C.R. and Thomas,R.J. (eds.), The geology of South Africa, Geological Society of South Africa and the Council for Geoscience, Pretoria

Munyanyiwa, H., Kroner, A. and Jaeckel, P. (1997). U-Pb and Pb-Pb single ages for charnoenderbites from Magondi mobile belt, northwest Zimbabwe. S. Afr. J. Geol., 98, 52-57.

Prokoph, A., Ernst, R.E. and Buchan, K.L. (2004). Time-series analysis of large igneous provinces: 3500 Ma to present. J. Geol., 112, 1-22.

Raines, G.L., Hastings, J.T., and Moyer, L.A. (2007). ArcGeology (version 1): A geodatabase design for digital geologic maps using ArcGIS. 22pp. http://support.esri.com/index.cfm?fa=downloads.dataModels.filteredGateway\&dmid=30

Ranganai, R.T., Kampunzu, A.B., Atekwana, E.A., Paya, B.K., King, J.G., Koosimile, D.I. and Stettler, E.H. (2002). Gravity evidence for a larger Limpopo Belt in southern Africa and geodynamic implications. Geophys. J. Int., 149, F9-F14. 
Schidlowski, M., Eichmann, R. and Junge, C.E. (1976). Carbon Isotope Geochemistry of Precambrian Lomagundi Carbonate Province, Rhodesia. Geochim. Cosmochim. Acta, 40, 449-455.

Steinshouer, W., Qiang, J., McCabe, P.J. and Ryder, R.T. (1999). Maps showing geology, oil and gas fields, and geologic provinces of the Asia Pacific region. U. S. G. S. Open File Report, 97-470F, 1-16.

Sumner, D.Y. and Beukes, N.J. (2006). Sequence stratigraphic development of the Neoarchean Transvaal carbonate platform, Kaapvaal Craton, South Africa. S. Afr. J. Geol., 109, 11-22.

Tinker, J., De Wit, M.J. and Grotzinger, J.P. (2002). Seismic stratigraphic constraints on Neoarchean - Paleoproterozoic evolution of the western margin of the Kaapvaal Craton, South Africa. S. Afr. J. Geol., 105, 107-134.

Treloar, P.J. and Kramers, J.D. (1989). Metamorphism and Geochronology of Granulites and Migmatitic Granulites from the Magondi Mobile Belt, Zimbabwe. Precambr. Res., 45, 277-289.

Wardle, R.J., Gower, C.F., James, D.T., St-Onge, M.R., Scott, D.J., Garde, A.A., Culshaw, N.G., Van Gool, J.A.M., Connelly, J.N., Perreault, S. and Hall, J. (2002). Correlation chart of the Proterozoic assembly of the northeastern Canadian - Greenland Shield. Can. J. Earth Sci., 39, 895. 


\section{Figures}

Figure 1. Schematic of the conceptual design of the StratDB database, illustrating the major tables, fields and some typical values. Tables shown primarily relate to the lithostratigraphic aspects of the database design and do not represent a formal entity-relationship diagram.

Figure 2. Schematic of the conceptual design of the StratDB database, illustrating the major tables, fields and some typical values for the lithostratigraphic, domain (deformation / metamorphism), large igneous province and ore deposit components of the system. Tables and links shown do not represent a formal entity-relationship diagram. Bold field names are primary keys.

Figure 3. Schematic of the conceptual design of the StratDB database, illustrating the major tables and fields required to construct time-space correlation charts.

Figure 4. Variables used, and stored in the database, to define the layout of polygons delimiting domains, lithostratigraphic units, metamorphic and deformation episodes.

Figure 5. View of the first part of detailed information for a lithostratigraphic unit. Users may navigate down the unit hierarchy by clicking on the sub-unit ID numbers or up the hierarchy by clicking on the "Go to parent" button when it is visible. In the example illustrated (Transvaal Supergroup from South Africa), there is no hierarchically higher lithostratigraphic unit, hence the button is not shown. Note that the software indicates whether geochronological data are available in DateView for the current or for any of the units one level lower in the hierarchy. Actual data are provided lower on the form (not shown).

Figure 6. Example download of query information for an hierarchical lithostratigraphic succession from southern Africa. The outline feature of Excel provides flexible control of which units are visible.

Figure 7. Legend illustrating the matrix of geodynamic settings (left) and rock classes (top) used to classify all lithostratigraphic units. Dyke swarms and pre-existing crust are classified independent of tectonic setting and rock class. Legend was created as a series of labelled polygons using the ArcMap component of ArcGIS.

Figure 8. Legend for environment of formation for lithostratigraphic units and of special features and geochronological method symbols. Legend was created as a series of labelled polygons and symbols using the ArcMap component of ArcGIS.

Figure 9. Miniature view of time-space correlation chart for the Palaeoproterozoic of southern Africa. Symbology is for the matrix of geodynamic settings and rock classes (see Figure 7). Lithostratigraphic unit labels have been omitted for clarity and a few labels (large grey text) have been added. Full version of this chart and of an equivalent for depositional setting are available as supplementary information (available online or on CD at back of volume). 
Figure 10. Locality map (copied from the full time-space correlation chart) for southern Africa. Domain extents and boundaries are shown over an aeromagnetic compilation of the region (provided by the Council for Geoscience, South Africa).

Figure 11. Extract from the southern African time-space correlation chart to illustrate features relevant to correlation of the upper Transvaal succession and overlying lithostratigraphic units. Automatic labelling by the GIS system has been omitted (to reduce confusion due to the reduction in size of the image) and selected labels have been added manually in a graphics package.

Figure 12. Extract from the southern African time-space correlation chart to illustrate aspects of the environment of deposition view. Automatic labelling by the GIS system has been omitted (to reduce confusion due to the reduction in size of the image) and selected labels have been added manually in a graphics package.

Figure 13. Extract from the southern African time-space correlation chart to illustrate aspects of correlation for the northern Kaapvaal Craton, various domains in the Limpopo Belt and the Magondi Belt of north western Zimbabwe. Symbology is based on geodynamic setting and rock class. Automatic labelling by the GIS system has been omitted (to reduce confusion due to the reduction in size of the image) and selected labels have been added manually in a graphics package.

Figure 14. Time slice maps for the Palaeoproterozoic evolution of southern Africa, using symbology for geodynamic setting $v s$ rock class and for sedimentary depositional environment. Maps were constructed in ArcGIS using linked attribute information from the StratDB database and GIS maps for South Africa (provided by the Council for Geoscience, South Africa), Namibia (provided by the Geological Survey of Namibia), Botswana (Key and Ayres, 2000), Zimbabwe (cut from the 1:5,000,000 geological map of Africa, Council for Geoscience, South Africa) and the 1:2,500,000 geological map of sub-Kalahari units (Council for Geoscience, South Africa). Time slices were selected to match logical breaks in sedimentation as identified in the time-space correlation chart of the area. 


\begin{tabular}{|c|c|c|c|c|}
\hline Geochronology & Lithostratigraphy & \multirow{3}{*}{$\begin{array}{l}\text { Tectonic } \\
\text { Metamorphic episodes } \\
\text { Metamorphic grade } \\
\text { Deformation episodes }\end{array}$} & Large Ign. Prov. & \multirow{2}{*}{$\begin{array}{l}\text { EconomIC } \\
\text { Host Unit }\end{array}$} \\
\hline Unit & Unit & & Unit & \\
\hline $\begin{array}{l}\text { Material } \\
\text { Isotope system } \\
\text { Interpretation }\end{array}$ & $\begin{array}{l}\text { Geodynamic setting } \\
\text { Rock class }\end{array}$ & & $\begin{array}{l}\text { Size } \\
\text { Morphology } \\
\text { Rating }\end{array}$ & $\begin{array}{l}\text { Deposit } \\
\text { Clan } \\
\text { Commodities } \\
\text { Info. Source }\end{array}$ \\
\hline Age + uncertainties & Age limits & Age limits & Age limits & Age limits \\
\hline $\begin{array}{l}\text { Location } \\
\text { Reference }\end{array}$ & GIS code & & Locality & Locality \\
\hline Domain & Domain & Domain & Domain & Domain \\
\hline
\end{tabular}

Figure 1 
Lithostratigraphic Information

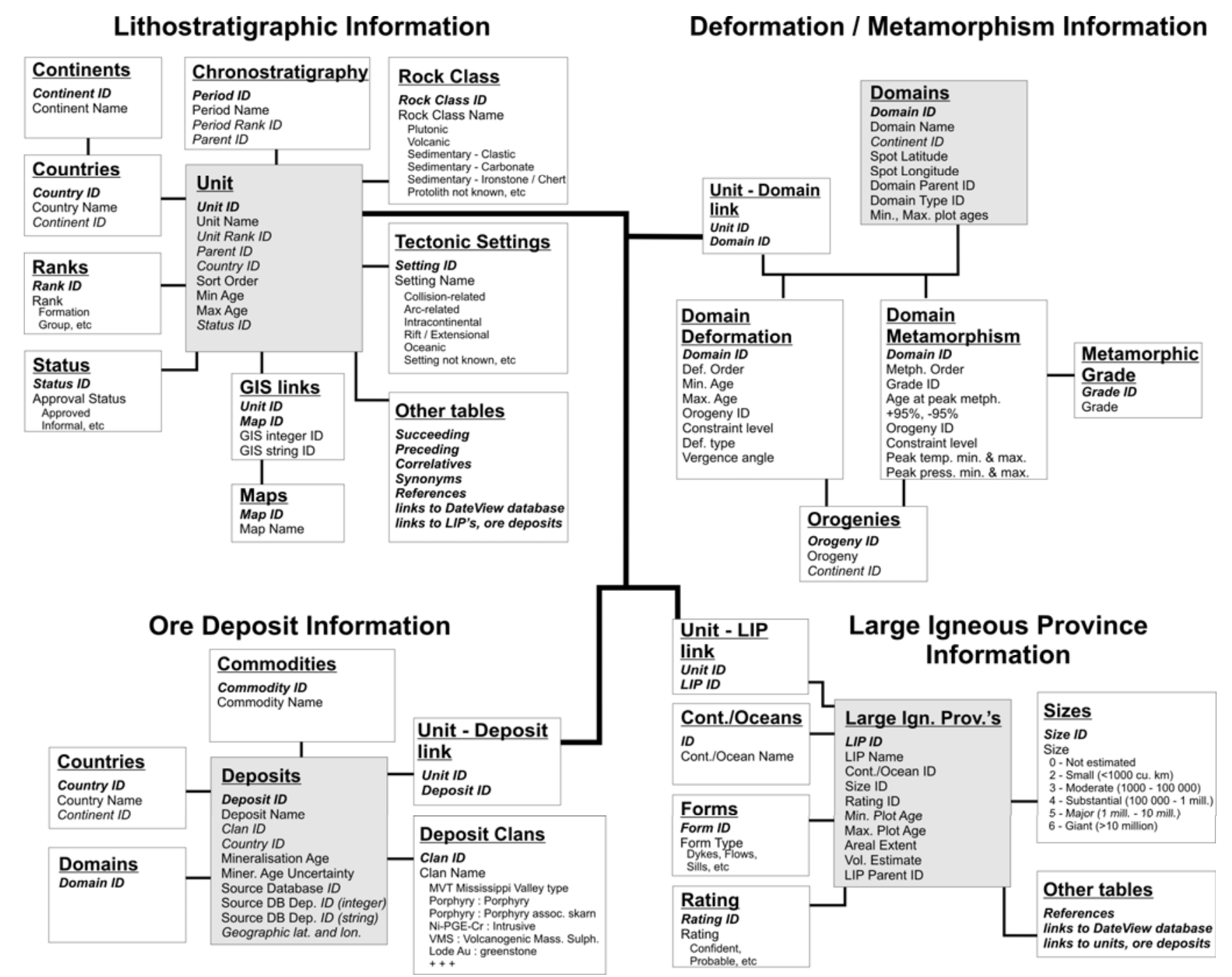

Figure 2 


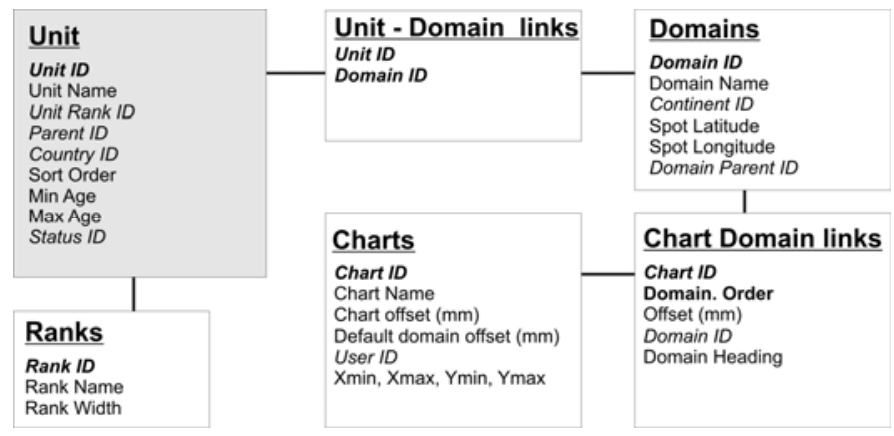

Figure 3

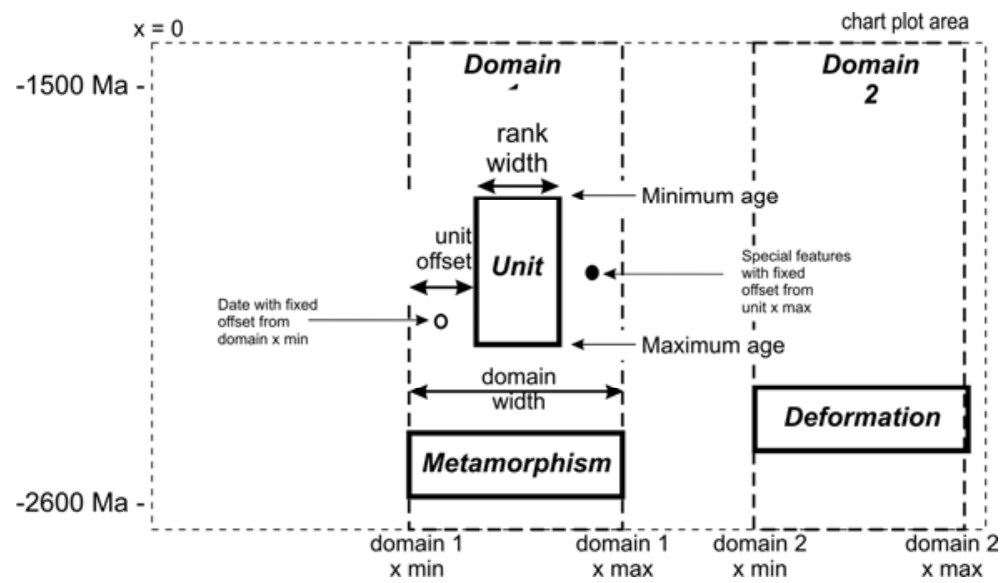

Figure 4 


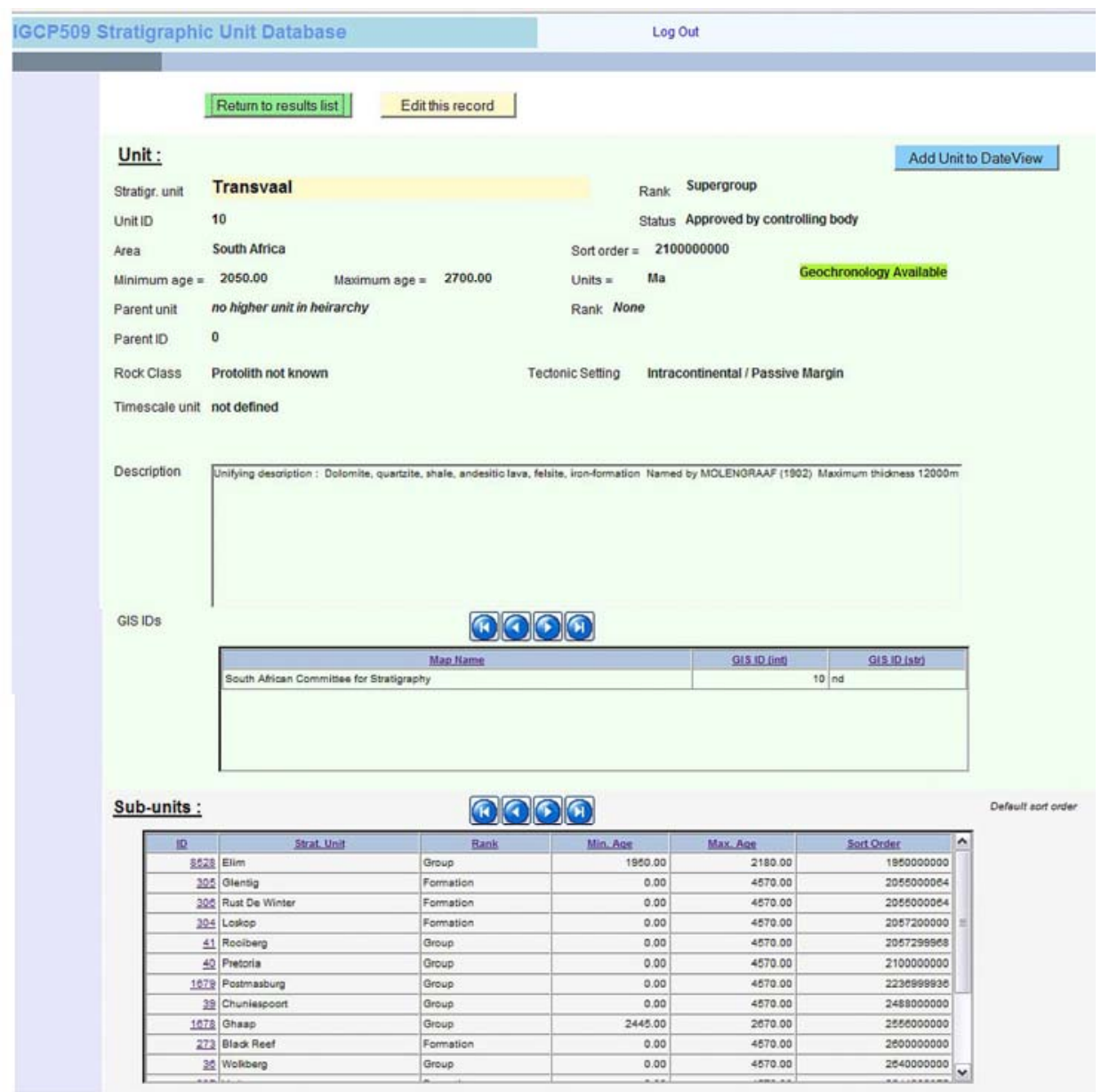

Figure 5 


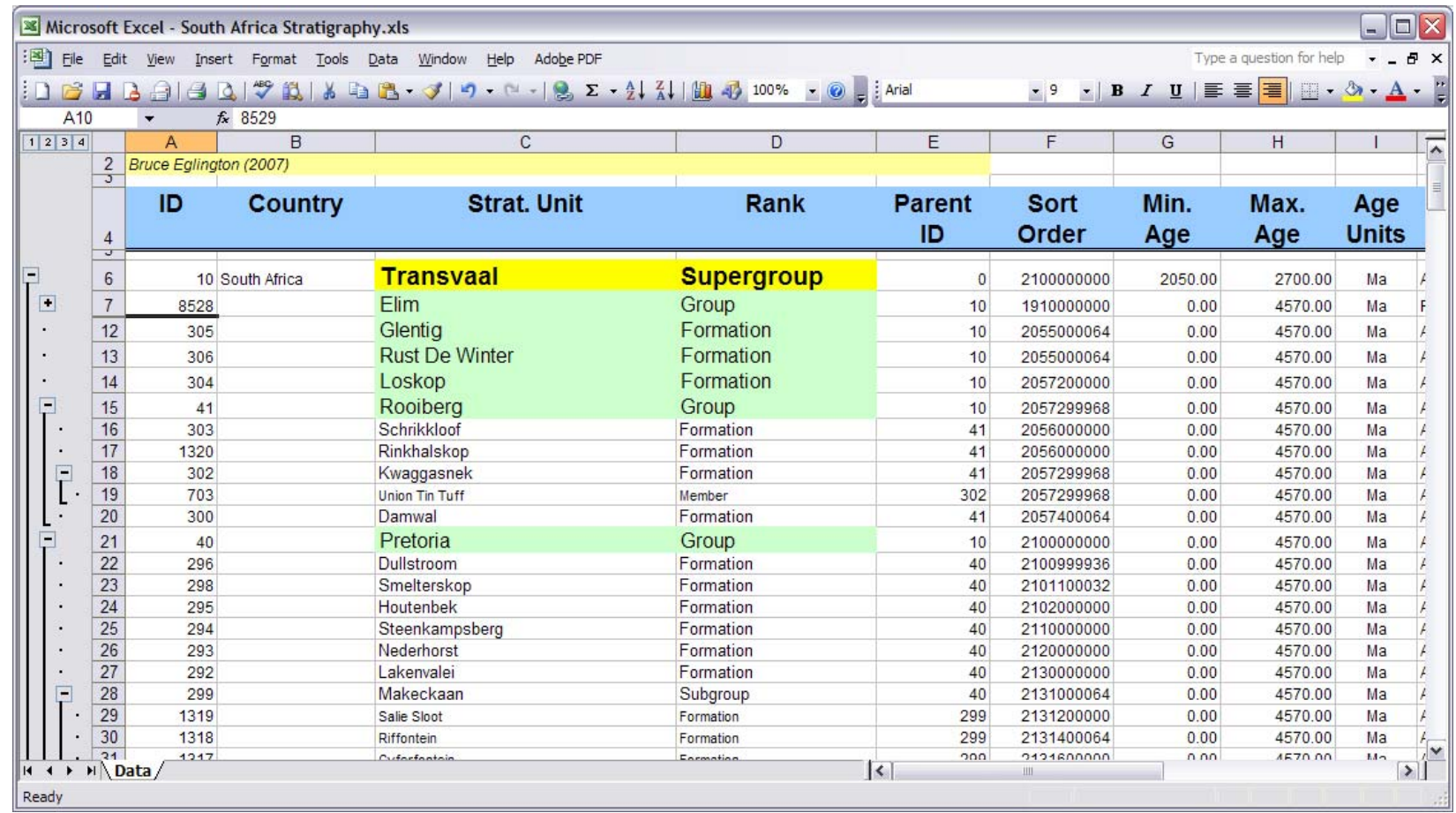

Figure 6

\section{Legend}

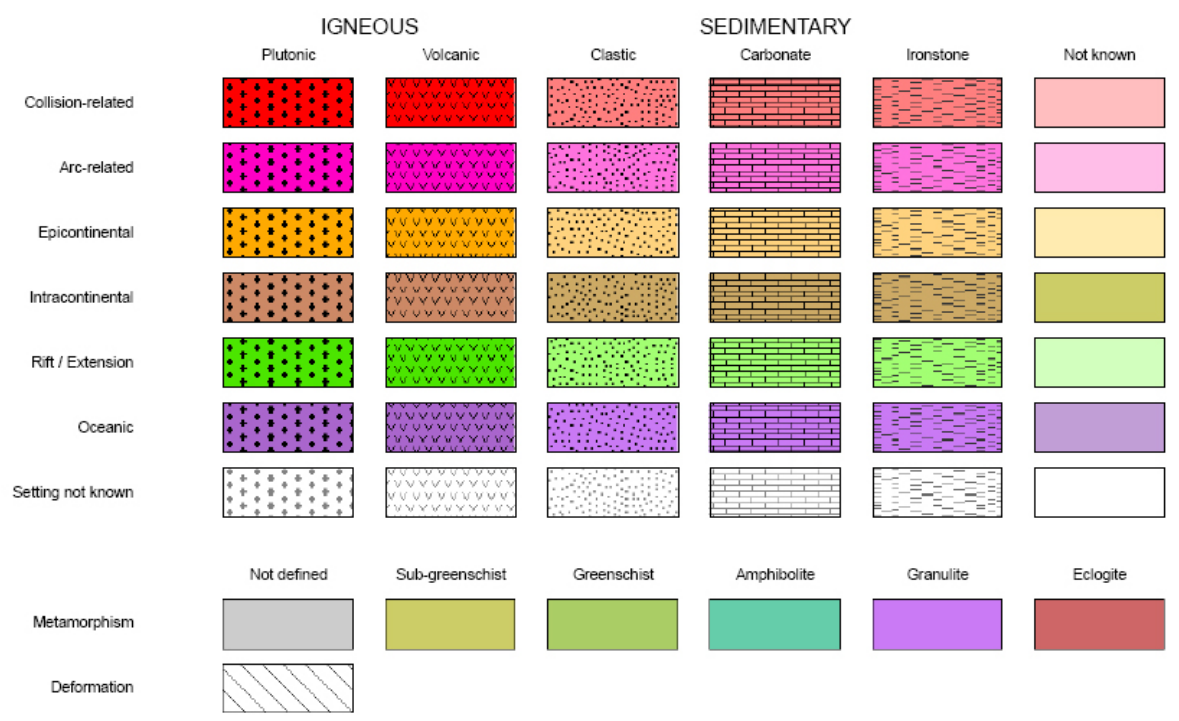

Figure 7 


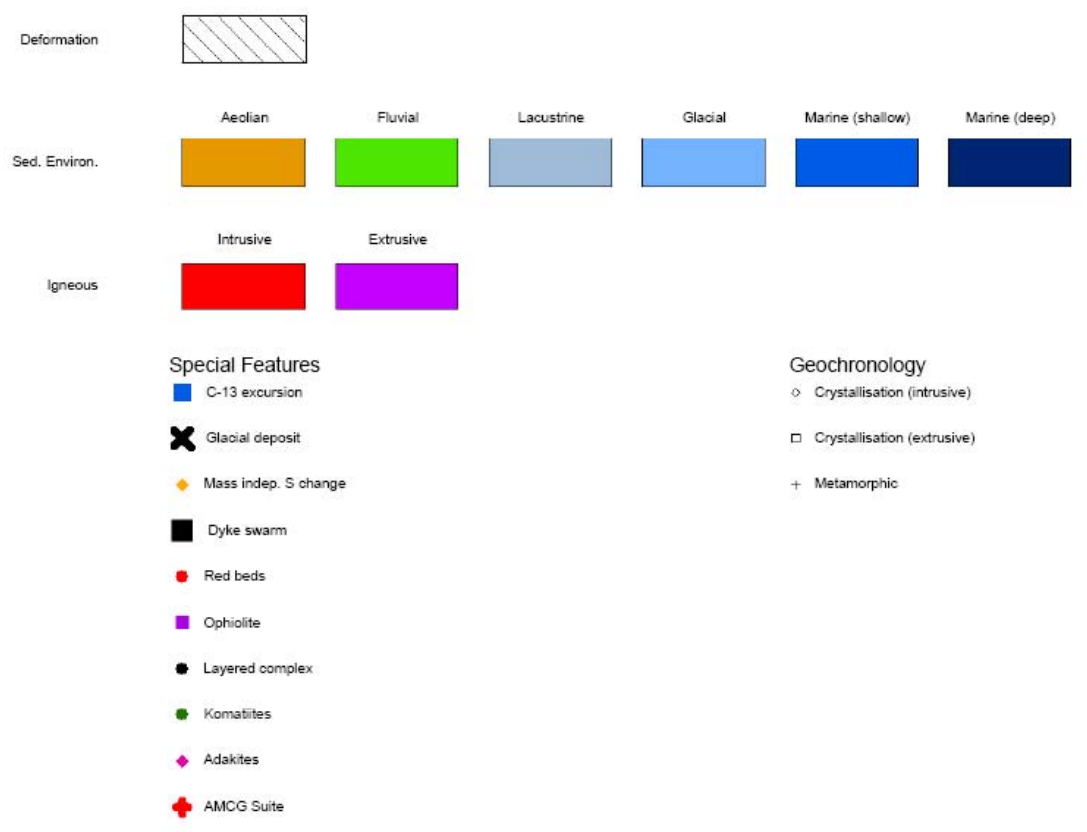

Figure 8 


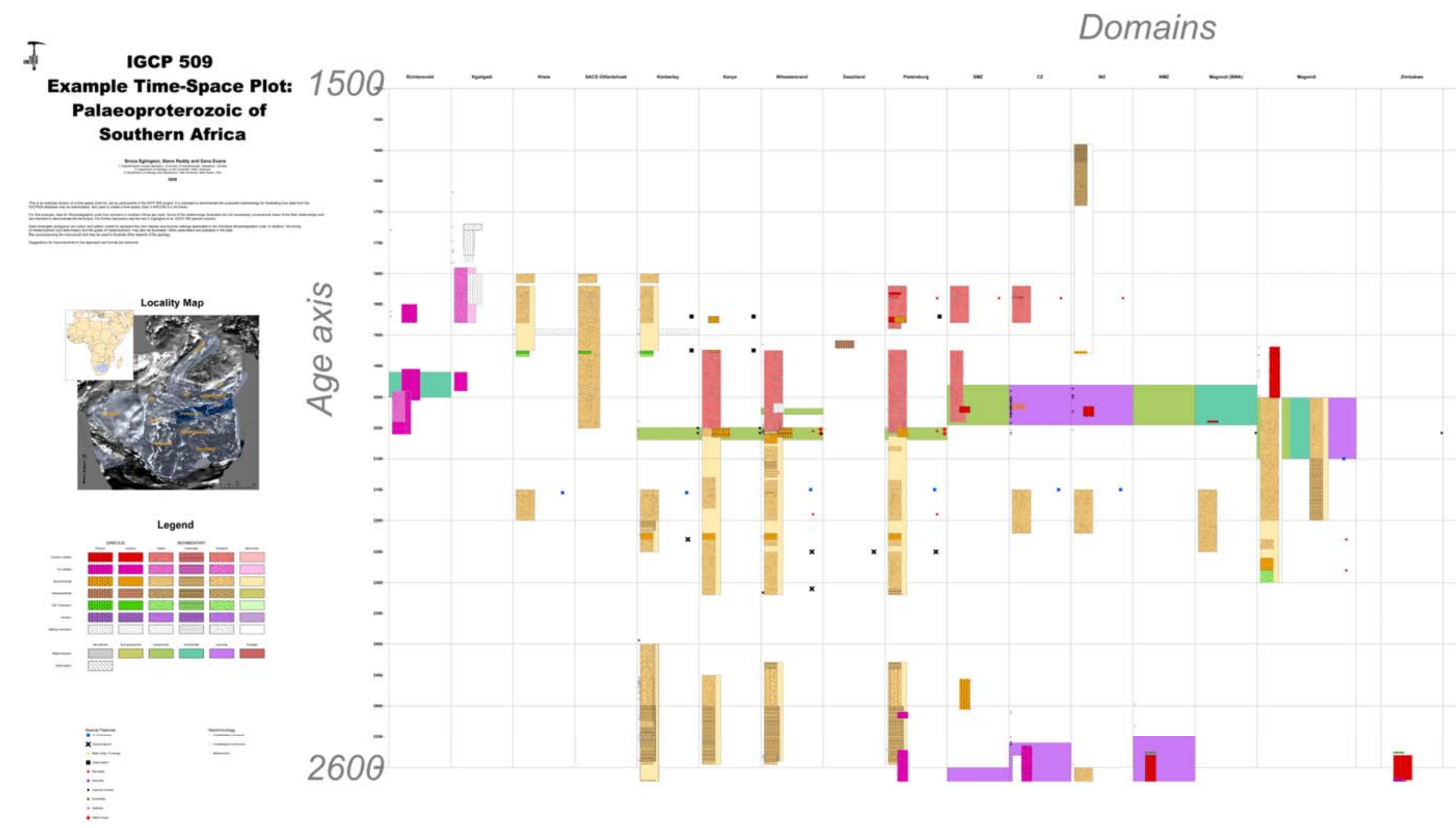

Figure 9 - preferably to span two pages 


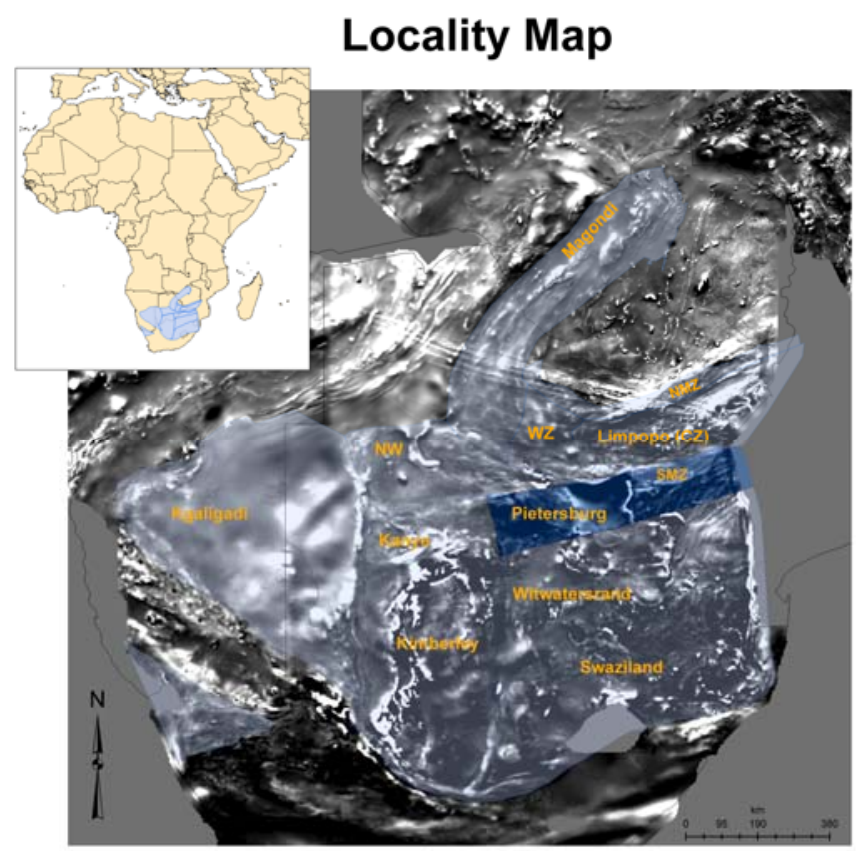

Figure 10 


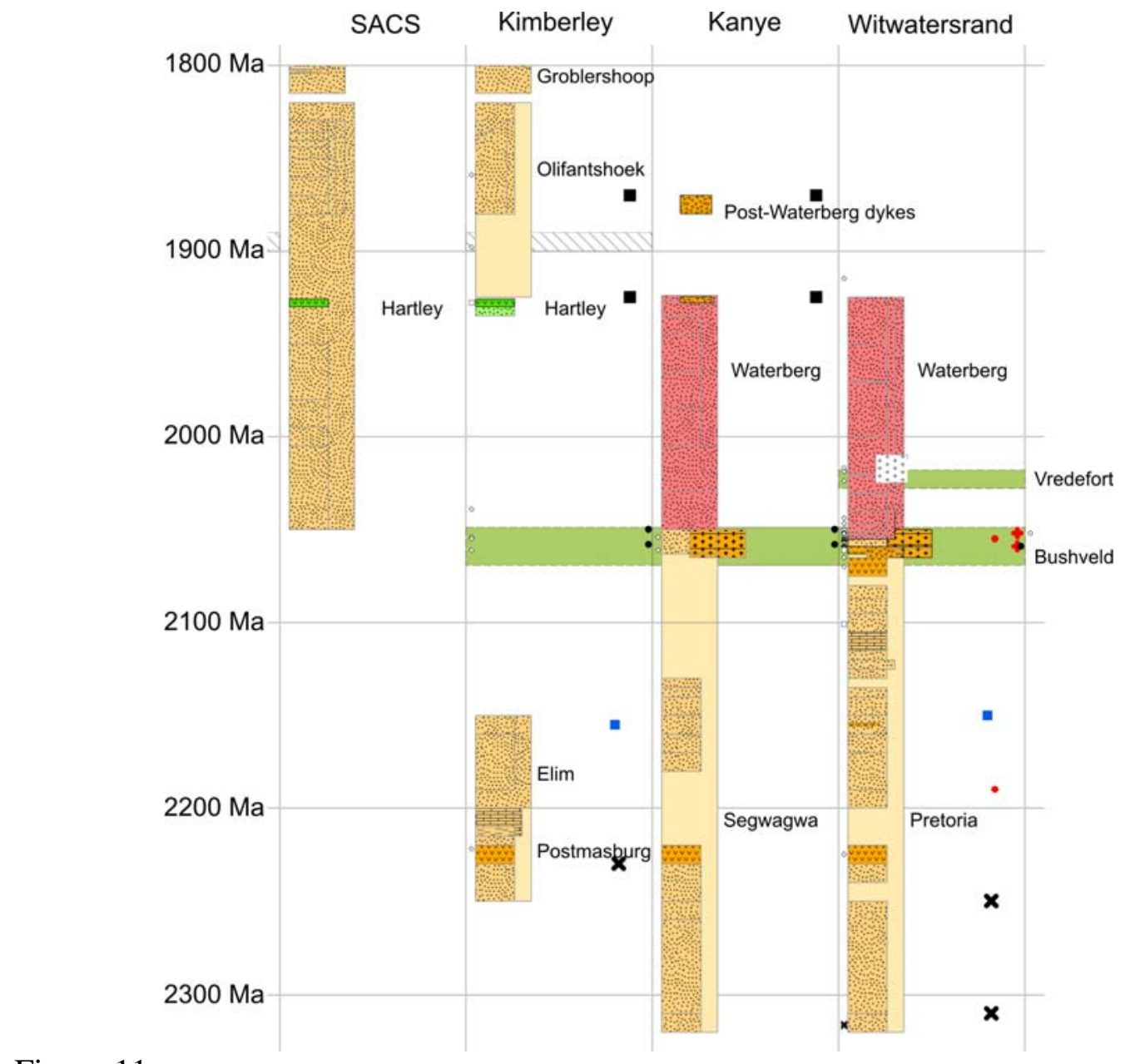

Figure 11 


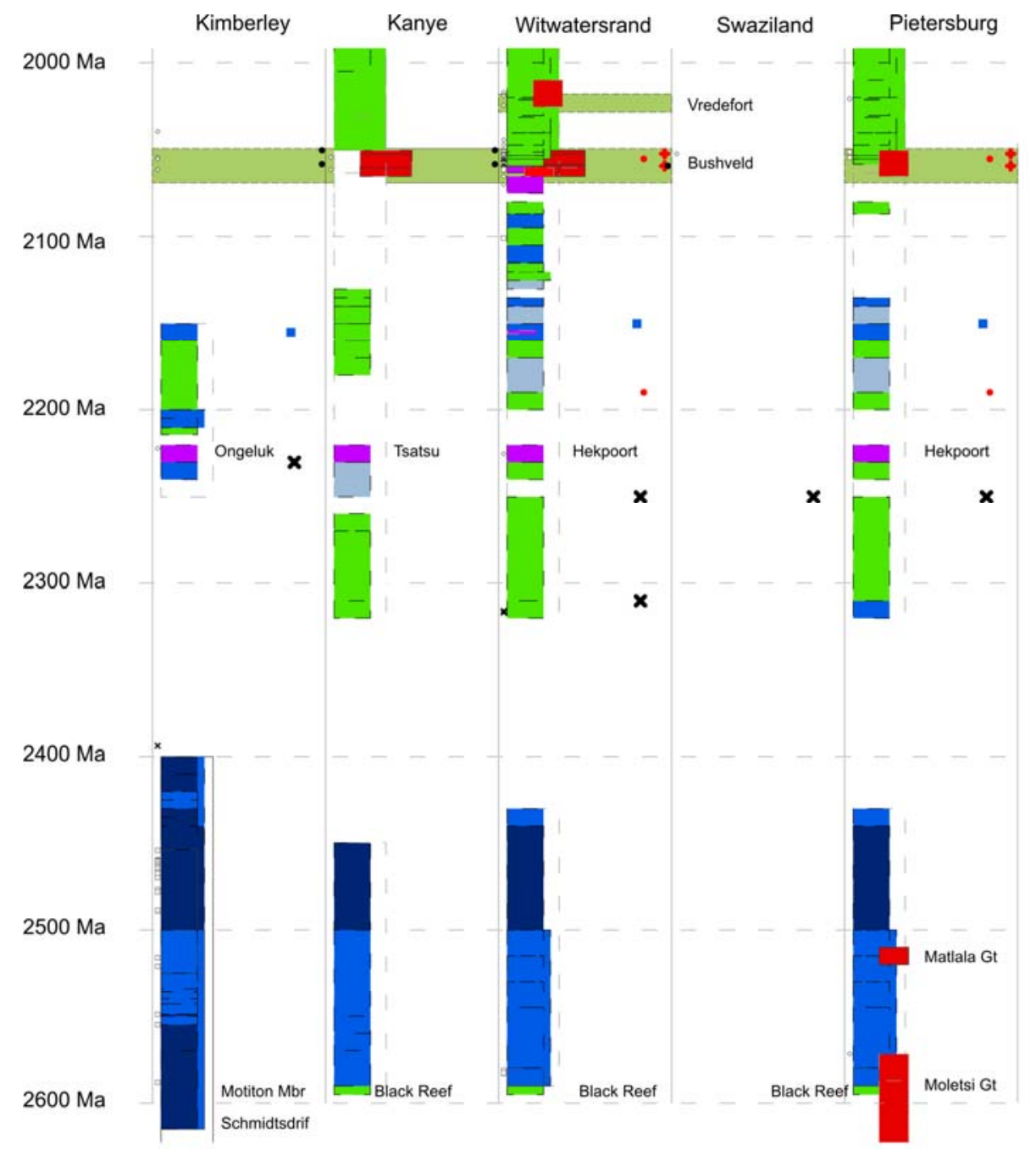

Figure 12 


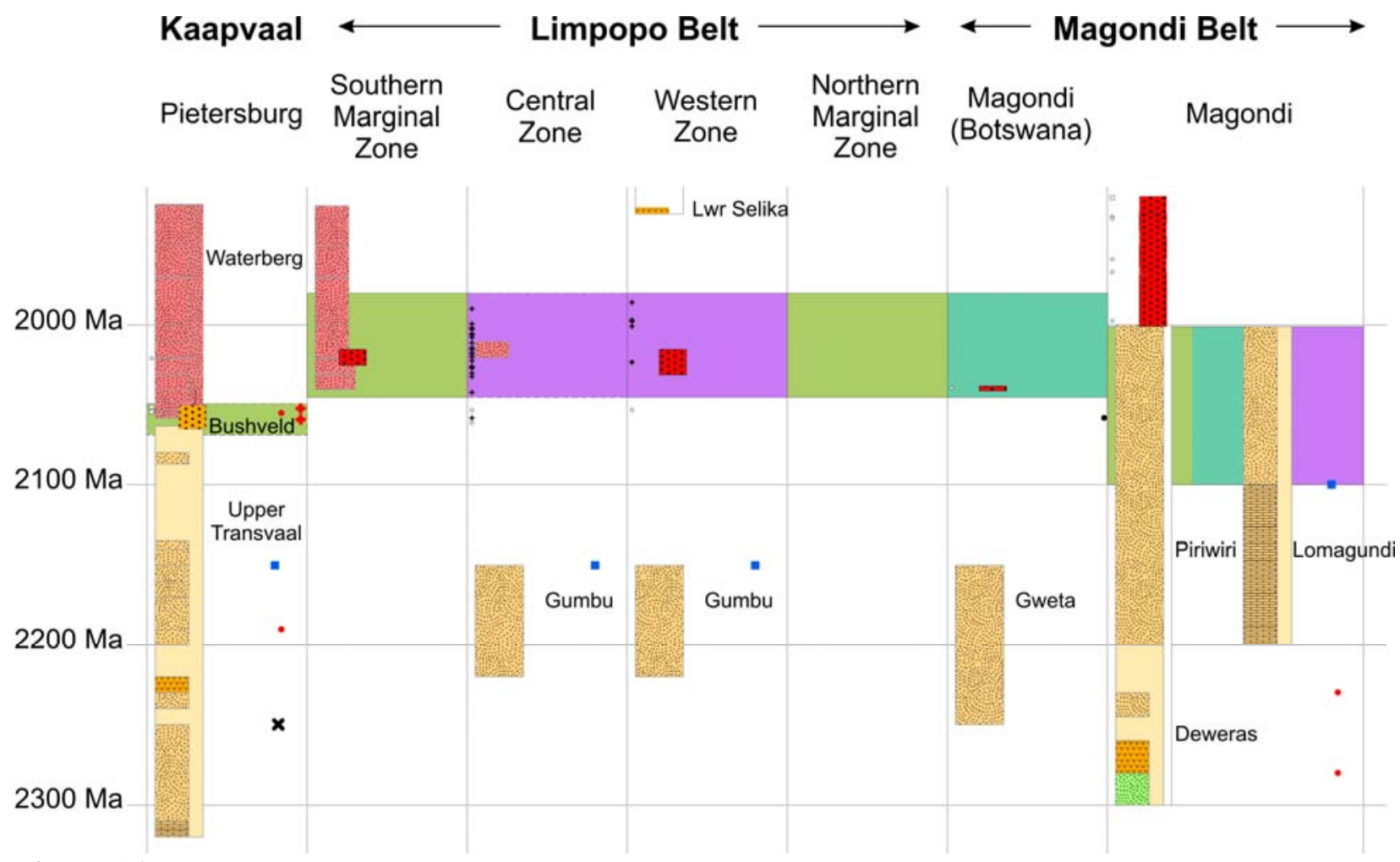

Figure 13 


\section{Geodynamic Setting and Rock Class}
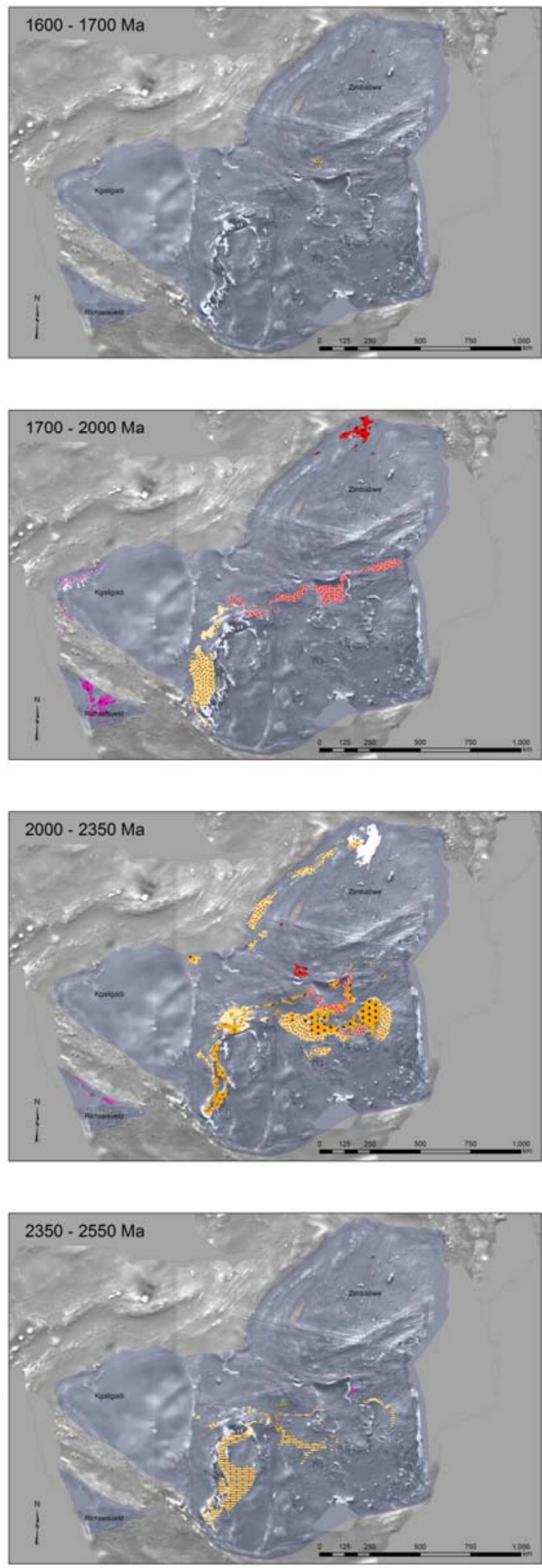

Depositional Environment
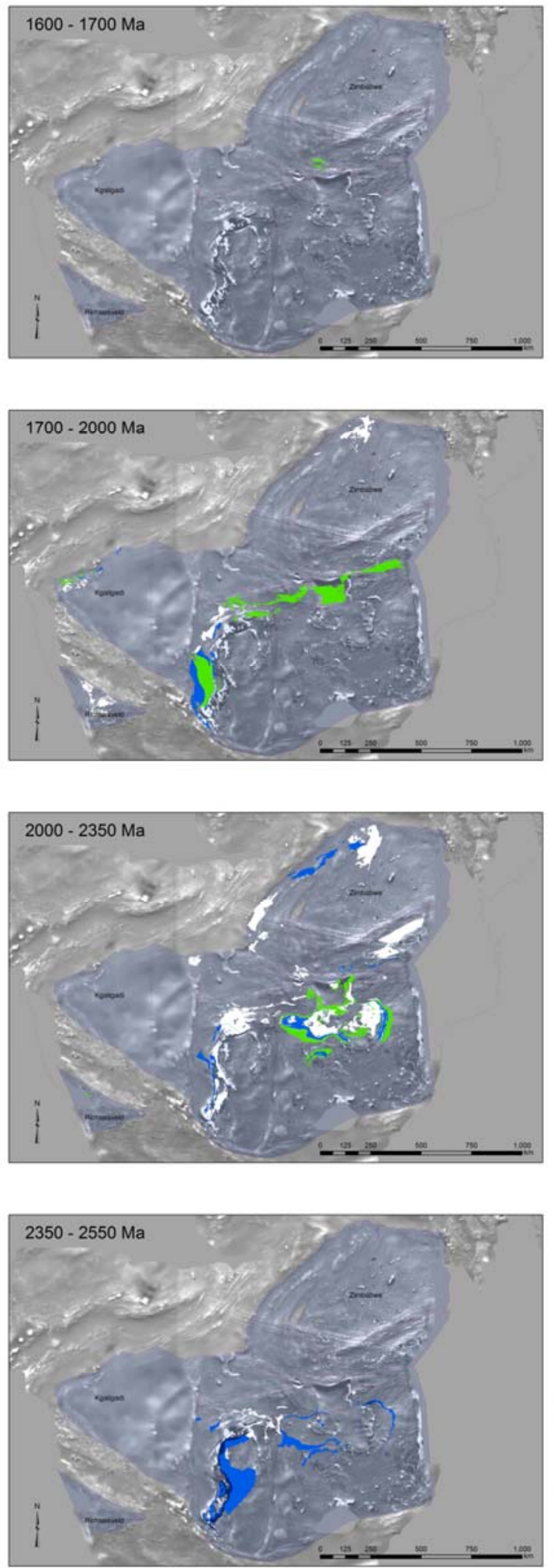

Figure 14 